\title{
CARACTERÍSTICAS E APLICAÇÕES DO GRAFENO E DO ÓXIDO DE GRAFENO E AS PRINCIPAIS ROTAS PARA SÍNTESE
}

\section{CHARACTERISTICS AND APPLICATIONS OF GRAPHENE AND GRAPHENE OXIDE AND MAIN ROUTES FOR SYNTHESIS}

\section{J. S. F. CAMARGOS ${ }^{1}$, A. O. SEMMER ${ }^{1}$ e S. N. SILVA ${ }^{1}$}

${ }^{1}$ Centro Federal de Educação Tecnológica de Minas Gerais (CEFET-MG), Departamento de Engenharia de Materiais (DEMAT), Brasil

julianasofia.cefetmg@gmail.com

\author{
article info \\ Article history: \\ Received 2017-09-04 \\ Accepted 2017-11-20 \\ Available online 2017-12-20
}

PALAVRAS-CHAVE: Grafeno; Óxido de grafeno; Síntese.

KEYWORDS: Graphene; Graphene Oxid; Synthesis.

\begin{abstract}
RESUMO: No presente artigo foi feita uma revisão bibliográfica a respeito das principais rotas de síntese do grafeno e os principais métodos de caracterização utilizados. O grafeno é um material bidimensional formado por átomos de carbono que se organizam em uma estrutura hexagonal. As rotas de sintese de grafeno podem ser divididas em dois tipos: bottom-up e top-down. A primeira parte de átomos simples de carbono para a formação da estrutura hexagonal e a segunda parte da grafita, material formado camadas de átomos de carbono ligados entre si formando hexágonos, e esfolia essas camadas afim de se obter apenas uma, que é o grafeno. As principais técnicas de caracterização utilizadas para a caracterização são Difração de raio X (DRX), Microscopia eletrônica de varredura (MEV), Microscopia eletrônica de transmissão (MET) e espectroscopia RAMAN, sendo que a última é a mais determinante.
\end{abstract}

\begin{abstract}
In the present article, a bibliographical review was made on the main routes of synthesis of graphene and the main characterization methods used. Graphene is a two-dimensional material made up of carbon atoms that organize into a hexagonal structure. Graphene synthesis routes can be divided into two types: bottom-up and top-down. The first part of simple carbon atoms for the formation of the hexagonal structure and the second part of the graphite, formed material layers of carbon atoms bonded together to form hexagons, and exfoliates these layers in order to obtain only one, which is graphene. The main characterization techniques used for the characterization are X-ray diffraction (XRD), Scanning Electron Microscopy (SEM), Electron Transmission Electron Microscopy (TEM) and RAMAN spectroscopy, the latter being the most determinant.
\end{abstract}

\section{INTRODUÇÃO}

O prêmio Nobel concedido em 2010 aos professores Andre Geim e Konstantin Novoselov, da Universidade de Manchester, despertou o interesse de pesquisadores do mundo inteiro em estudar o grafeno, material que tem sido considerado uma das formas 
alotrópicas do carbono mais promissoras para aplicações tecnológicas. Isso porque ele apresenta uma série de características peculiares, como resistências térmica e mecânica elevadas, boa condutividade elétrica, dentre outras, que podem ter uma ampla gama de aplicações. O grafeno, de acordo com a IUPAC (apud, 2017), consiste em uma folha plana de átomos de carbono em ligação $\mathrm{sp}^{2}$ densamente compactados e com espessura de apenas um átomo, reunidos em uma estrutura cristalina hexagonal. Já os óxidos de grafeno são estrutura derivada do grafeno caracterizada pela presença de grupos funcionais oxigenados (hidroxila, carbonila e epóxi) na superfície e extremidades da folha de carbono. Os óxidos de grafeno apresentam vantagens em relação ao grafeno como melhor solubilidade e estabilidade em meio aquoso (WICK, P. et al., 2014).

Estudos experimentais e teóricos relativos à síntese e às propriedades do grafeno e do óxido de grafeno vinham sendo realizados desde meados do século XIX. Entretanto, sua maior popularidade foi motivada, em parte pelo desenvolvimento dos nanotubos de carbono, a partir da década de 1990 e por esse trabalho de Novoselov et al., publicado em 2004, no qual foram confirmados experimentalmente os efeitos físicos previstos em estudos teóricos. (WHITENER, 2014).

Ao redor do mundo, investigações buscam em diversos campos do conhecimento o aumento da performance e/ou elevação dessas propriedades físicas. A meta tem sido oferecer à indústria a opção de um novo material para a produção de condutores transparentes, eletrodos flexíveis para células fotovoltaicas, transistores, sensores, nanocompósitos, recobrimento de materiais, etc. (SOLDANO et al., 2010).

O grafeno tornou-se um dos focos principais das pesquisas na engenharia de materiais, como evidenciado pelo recente anúncio da Comissão Europeia de um fundo de mais 1 bilhão de dólares para financiamento dos projetos de pesquisa e da comercialização de grafeno nos próximos sete anos. Apesar das várias aplicações, o uso de grafeno ainda é restrito, pois sua reprodutibilidade e produção em larga escala permanecem desafiadoras (BADHULIKA, 2015; SHAH, 2015). Há um enorme interesse em desenvolver rotas de preparação que sejam viáveis do ponto de vista prático, com elevado rendimento e pureza e boa qualidade estrutural (MEHL et al., 2014). Assim, o presente artigo tem como objetivo reunir os conceitos mais importantes, informações relativas às principais rotas de síntese de grafeno e as principais técnicas de caracterização desse material, visando o melhor entendimento dos processos.

\section{METODOLOGIA}

Revisão bibliográfica de artigos, monografias e dissertações sobre as diferentes rotas de síntese de grafeno, com foco na escala de produção e na qualidade do produto.

\section{RESULTADOS E DISCUSSÃO}

\subsection{Características e aplicações do grafeno}

O carbono é um elemento da coluna 4A da tabela periódica, possuindo seis elétrons, dentre os quais dois estão fortemente ligados ao núcleo e quatro estão na camada de valência. Em sua forma elementar, os átomos ocupam os orbitais $2 s, 2 p x, 2 p y$ e $2 p z$. Ao se ligarem a outros átomos de carbono, estes orbitais se combinam e formam novos orbitais, chamados híbridos, em um processo chamado hibridização (WONG e AKINWANDE, 2011). 
A hibridização pode ocorrer de três formas: hibridização $s p$, hibridização $s p 2$ e hibridização $s p 3$. Na hibridização $s p$, o orbital $s$ se combina apenas com um dos orbitais $p$, formando dois orbitais $s p$. Na hibridização $s p 2$, um orbital s combina-se a dois orbitais $p$ ( $p x$ e $p y$ ), formando três orbitais $s p 2$ no plano $x y$. Na hibridização $s p 3$, o orbital s e combinado a três orbitais $p$ ( $p x, p y$ e $p z$ ), formando quatro orbitais. (WONG e AKINWANDE, 2011).

O grafeno é um material bidimensional com espessura monoatômica formado por átomos de carbono com hibridação sp2 ligados entre si em estrutura hexagonal. Atualmente, porém, o termo grafeno tem sido utilizado de forma um pouco mais ampla, abrangendo não só o material original, composto de uma única folha, mas também a uma família de materiais formados por mais folhas de grafeno empilhadas de forma organizada (MEHL et al., 2014). A figura abaixo ilustra sua estrutura.

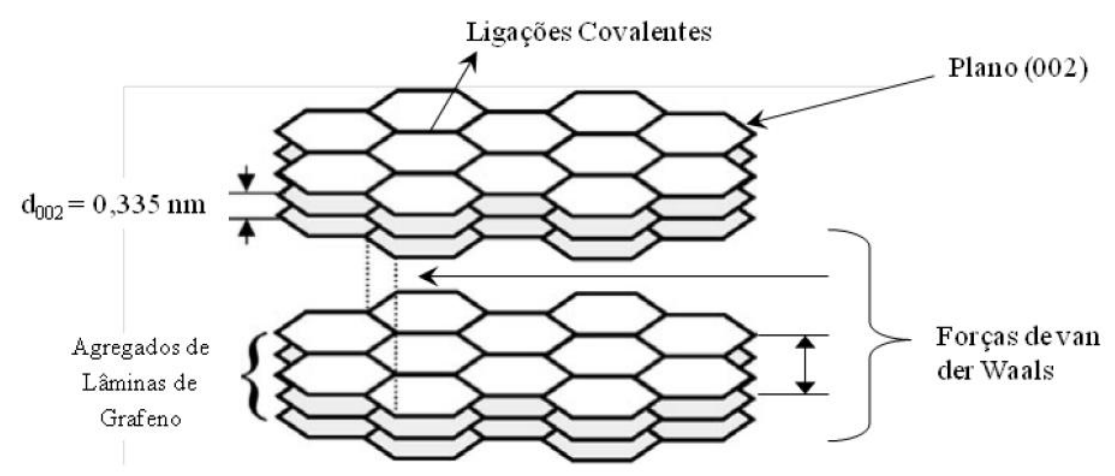

Figura 1 - Estrutura do grafeno.

Aplicações: Uma busca na literatura envolvendo grafeno possibilita um levantamento abundante sobre aplicações em potencial deste material em várias áreas, sendo que a com maior possibilidade de aplicação é a de materiais compósitos, principalmente com polímeros. A introdução de pequenas quantidades (de $0,01 \%$ em massa até $5 \%$ ) de grafeno em materiais poliméricos pode levar a aumento de condutividade, da resistência mecânica e química, e melhora nas propriedades térmicas. (ZARBIN, 2013). Outra área que vem tendo destaque é a de energia. O grafeno atua como material para a camada transportadora de elétrons em células solares orgânicas e flexíveis, aumentando o rendimento destes dispositivos. Vem também sendo usados, puros ou em diferentes compósitos, em supercapacitores, incluindo supercapacitores flexíveis, com altíssima performance (ZARBIN, 2013). Destacam-se também as áreas de sensores, biosensores, eletrônica, purificação e descontaminação de água.

\subsection{Rotas}

Dentre os vários métodos de síntese de grafeno apresentados na literatura, destacamse os processos de bottom-up, que se baseia na manipulação de átomos simples de carbono, como metano e etanol, e top-down, que consiste na separação das camadas empilhadas de grafita produzindo folhas individuais (CORDEIRO et al., 2015).

Bottom-up: No processo bottom-up, destacam-se a síntese do grafeno por meio dos métodos de crescimento epitaxial e deposição química de vapor (CVD). 
Crescimento epitaxial é um processo que consiste em submeter um cristal de $\mathrm{SiC}$ à temperaturas elevadas de modo que átomos de Si localizados no topo do cristal dessorvam e átomos de carbono organizem-se formando estruturas grafíticas. À medida que a Si sublima, novas camadas de grafeno são obtidas e vão se sobrepondo, de forma que a quantidade de camadas empilhadas e o tamanho da rede depende da estrutura do mineral.
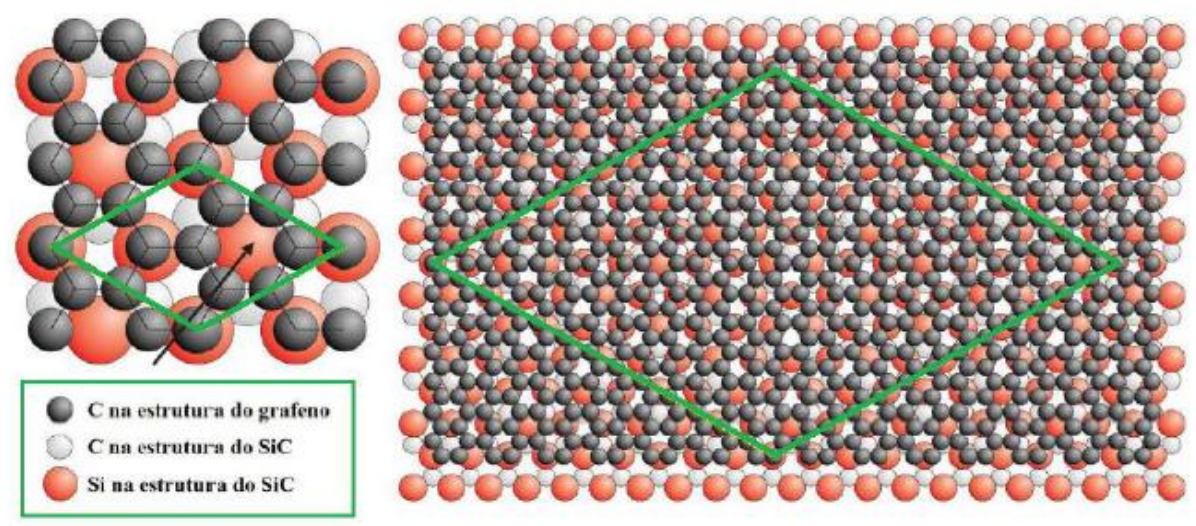

Figura 2 - Crescimento de grafeno por crescimento epitaxial sobre substrato de $\mathrm{SiC}$.

Ainda não existe tecnologia para controlar tais variáveis. Além disso, algumas propriedades eletrônicas do grafeno são alteradas quando ele é produzido dessa maneira. $\mathrm{O}$ custo do processo é elevado por ser realizado em vácuo, apesar de que já existem pesquisas que mostram que também pode ser feito em atmosfera com alguns gases específicos, o que barateia um pouco, mas continua impraticável para escala comercial. (CASTRO, 2011).

Já a deposição química de vapor é baseada na decomposição de precursores de carbono (hidrocarbonetos, álcoois, etc.) em fornos com atmosfera e temperatura controlados, sobre catalisadores metálicos adequados (ZARBIN, 2013). Nesse processo, o grafeno se forma em filme único sobre um substrato metálico, que funciona como catalizador. (SANTOS, 2016). Esses metais, como níquel, cobre, cobalto e rubídio, são indicados para o processo por possuírem elevados pontos de fusão e ebulição e por terem grande quantidade de elétrons e orbitais, o que facilita na quebra das ligações das moléculas. O grafeno que cresce sobre cada metal apresenta certas variações em suas propriedades. Essas variações também dependem da temperatura e do fluxo de gás utilizados durante a produção.

Um desafio para se utilizar essa técnica é o controle da uniformidade dos filmes, apesar de já existirem pesquisas relacionadas à essa otimização. Em contrapartida, a transferência desses filmes pode ser realizada para diferentes superfícies, facilitando as possíveis aplicações.

Top-down: O grafeno produzido utilizando esse método pode ser obtido a partir da separação da grafita por meio de uma esfoliação mecânica ou química. 


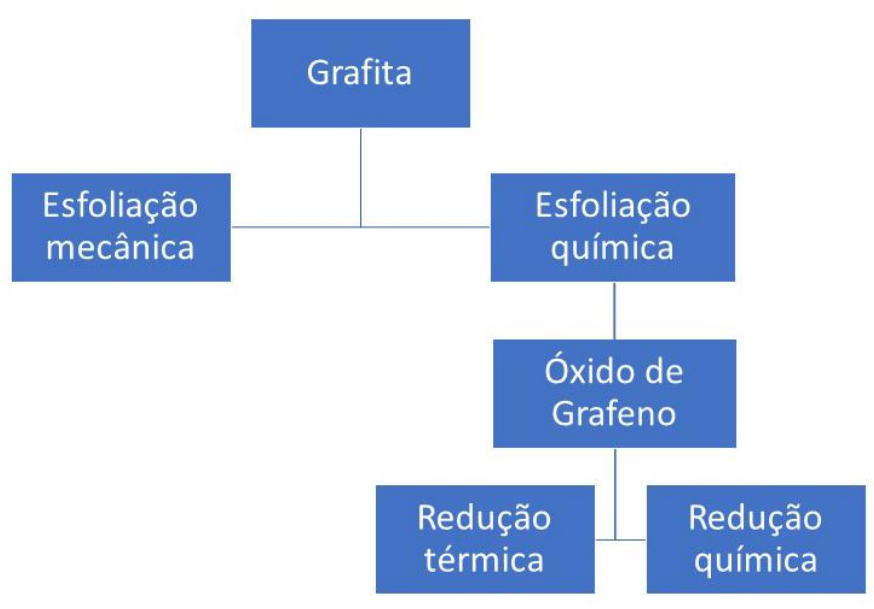

Figura 3 - Esquema dos processos Top-down.

A grafita é um alótropo do carbono (assim como o diamante, o fulereno e os nanotubos) formado por camadas de átomos ligados entre si em estrutura hexagonal. Cada camada que compõe a grafita é uma lâmina de grafeno (FIM, 2012).

$\mathrm{Na}$ esfoliação mecânica, é feita a descamação das camadas de grafeno de um floco de grafita com o auxílio de uma fita adesiva, por meio de movimentos de "colagem e descolagem", como é mostrado na figura 4, o que provoca uma clivagem preferencialmente nos planos cristalinos e deixa expostos os planos atômicos. Após esse processo, é feita a remoção do material da fita por um banho em solução com acetona, junto a um substrato de dióxido de silício $\left(\mathrm{SiO}_{2}\right)$, onde o grafeno fica retido (NOVOSELOV et al., 2004). Para obter uma única camada de grafeno, esse procedimento deve ser realizado várias vezes.

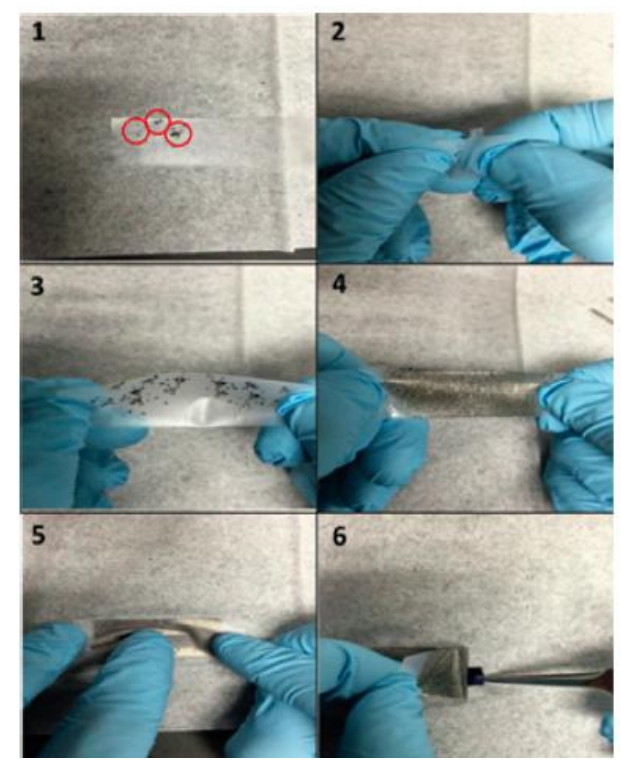

Figura 4 - Etapas da esfoliação mecânica. 
Esse método produz um grafeno com perfeita cristalinidade e com poucos defeitos em sua estrutura, porém a produtividade é limitada, por ser artesanal, e o custo do produto final é elevado devido ao baixíssimo rendimento, o que torna o método inviável.

Já a esfoliação química consiste na oxidação da grafita por ação de agentes oxidantes fortes como ácido sulfúrico, ácido nítrico, permanganatos e cloratos, onde íons são intercalados a estrutura da grafita, ampliando o espaço interplanar. $\mathrm{O}$ material resultante desse processo é chamado de grafite intercalado. Em seguida da oxidação, é necessário submeter o grafite intercalado a uma esfoliação, com auxílio de ultrassom por exemplo, que separa camadas da grafita, gerando o grafeno (HUMMERS, 1958). Dentre as diferentes rotas de esfoliação química existentes, destacam-se as desenvolvidas por, Staudenmaier, Hofmann e Hummers.

$\mathrm{O}$ método de Staudenmaier utiliza ácido nítrico fumegante $\left(\mathrm{HNO}_{3}\right)$, ácido sulfúrico concentrado $\left(\mathrm{H}_{2} \mathrm{SO}_{4}\right)$ e clorato de potássio $\left(\mathrm{KClO}_{3}\right)$. Já o método de Hofmann utiliza ácido nítrico concentrado $\left(\mathrm{HNO}_{3}\right)$, ácido sulfúrico concentrado $\left(\mathrm{H}_{2} \mathrm{SO}_{4}\right)$ e clorato de potássio $\left(\mathrm{KClO}_{3}\right)$. Por fim, o método de Hummers utiliza ácido sulfúrico concentrado $\left(\mathrm{H}_{2} \mathrm{SO}_{4}\right)$, nitrato de sódio $\left(\mathrm{NaNO}_{3}\right)$ e permanganato de potássio $\left(\mathrm{KMnO}_{4}\right)$.

O grafeno produzido pelo método de Staudenmaier e de Hofmann tem características mais semelhantes entre si do que o produzido de acordo com Hummers, já que os dois primeiros partem de $\mathrm{KClO}_{3}$ e ácido nítrico, e o segundo tem como base o permanganato de potássio. Essa variação gera grafenos com propriedades eletroquímicas bem distintas $(\mathrm{POH}$, 2012). Há ainda, um outro método de produção de grafeno, extremamente eficiente e barato, utilizando radiação eletromagnética (laser de um gravador de DVD) sob um filme de óxido de grafite produziu uma camada de grafeno de qualidade e mecanicamente muito resistente, podendo funcionar como capacitor ou substrato de semicondutor.

A síntese por esses métodos é amplamente estudada devido ao baixo custo e a possibilidades de produção em larga escala. Entretanto, a ação dos oxidantes causa defeitos na estrutura do mineral. O material resultante do processo é um óxido de grafeno com uma série de grupos funcionais ligados e falhas na rede hexagonal. Esses grupos podem facilitar a interação com outros materiais, contribuindo por exemplo para a produção de compósitos poliméricos, mas pode também interferir nas propriedades elétricas do produto final. Alguns desses grupos podem ser vistos na figura abaixo (Figura 5).

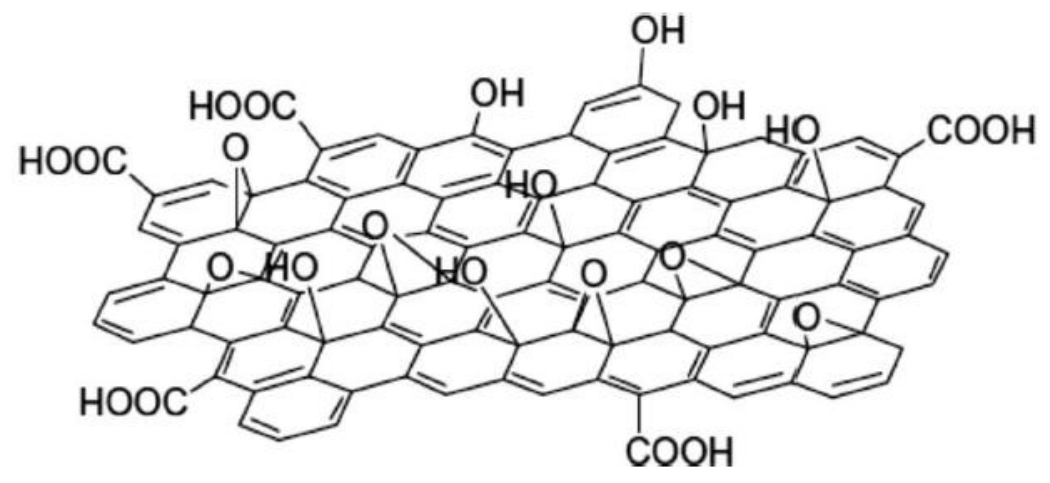

Figura 5 - Representação da estrutura do óxido de grafeno com exemplos de grupos funcionais que podem ficar ligados ao óxido de grafeno. 
A falta de homogeneidade da estrutura e presença de defeitos está diretamente relacionada ao grau de oxidação, que é determinado por sua vez pelo processo de produção (Figura 6).
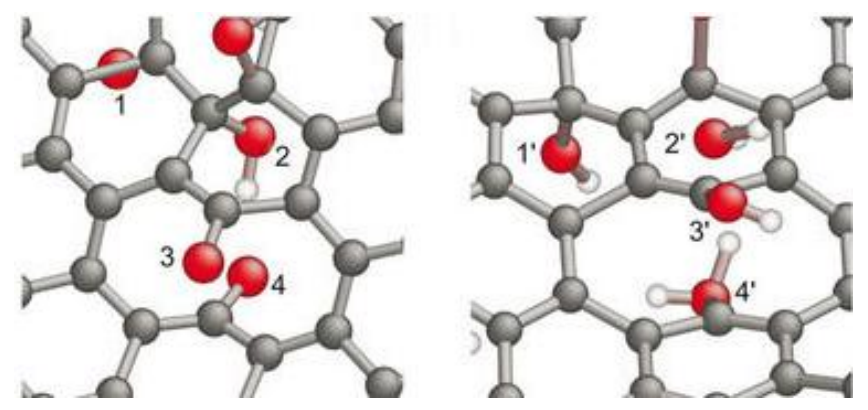

Figura 6 - Defeitos de estrutura gerados por grupos funcionais.

Se a quantidade de grupos funcionais precisar ser minimizada, torna-se necessário adicionar uma etapa de redução, que pode ser química ou térmica. Ela tem como objetivo restaurar as ligações $\pi$ e reestabelecer a condutividade elétrica do material, eliminando os radicais anexados e reestabelecendo a rede grafítica característica do grafeno.

No processo de redução química, o óxido de grafeno é esfoliado por meio de uma dispersão coloidal com redutores, tais como hidrazina, dimetilidrazina e boro-hidreto seguido de hidroquinona. Por outro lado, a redução térmica se baseia no rápido aquecimento de óxido de grafeno liberando moléculas de $\mathrm{CO}, \mathrm{CO}_{2}$ e $\mathrm{H}_{2} \mathrm{O}$, o que aumentam a pressão interna da estrutura e forçam a separação das folhas (MCALLISTER, 2007).

O tratamento com campos elétricos ou radiação eletromagnética também vem sendo utilizado, com o objetivo de redução do óxido de grafeno. A Figura 7 apresenta esquema de transformação de óxido de grafeno em óxido de grafeno reduzido parcialmente ou totalmente.

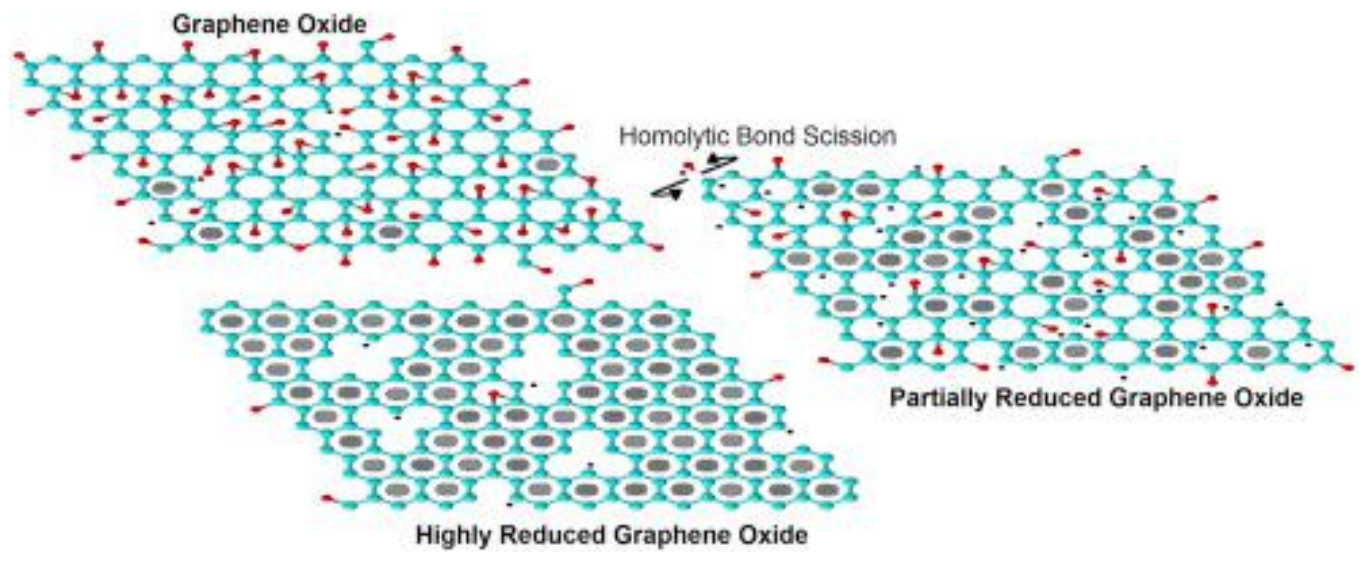

Figura 7 - Representacao da estrutura do óxido de grafeno e óxido de grafeno reduzido parcialmente ou totalmente.

Apesar de ser um método de preparação que tem ganhado destaque nos últimos anos, incluindo na produção de amostras comerciais, o número de variáveis envolvidas no processo 
é extremamente elevado, e uma pequena mudança em uma dessas variáveis pode levar a materiais com propriedades e características bastante distintas. Tal complexidade torna complicada a comparação entre amostras produzidas por procedimentos diferentes ou inclusive a reprodutibilidade de resultados uma vez já obtidos (MEHL et al., 2014).

Em suma, pode-se concluir que cada rota apresenta vantagens e desvantagens, sendo, portanto, necessário avaliar o custo benefício de cada processo e a aplicação final do grafeno que será produzido. A escalabilidade e custo de produção são parâmetros essenciais para a escolha de um determinado método.

\subsection{Técnicas de caracterização}

Difração de raio $\mathrm{X}$ (DRX): A Figura 8 mostra os difratogramas do grafite, grafeno e do óxido de grafeno. Em detalhes nesta mesma figura são mostrados para efeito de comparação os difratogramas de raios $\mathrm{X}$ normalizados das amostras de grafite, óxido de grafeno (GO) e óxido de grafeno reduzido (RGO) a partir do pó de grafite. O pico de difração em torno de $2 \theta=11^{\circ}$ na figura apresenta a distância interplanar de $0,860 \mathrm{~nm}$, sendo maior que o valor verificado para o grafite que é de $0,340 \mathrm{~nm}\left(2 \theta=26^{\circ}\right)$. Este aumento se deve à intercalação de grupos funcionais oxigenados (carbonilas, carboxilas, epóxido, hidroxilas) entre as folhas do grafite. Deste modo, é possível identificar a presença do óxido de grafeno e do grafeno.
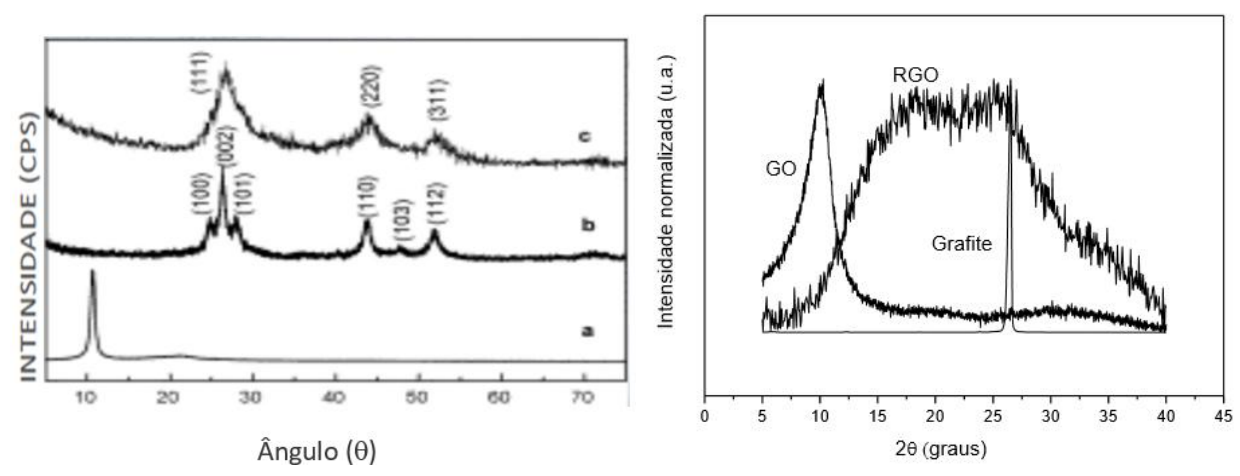

Figura 8 - Difratogramas de raios X das amostras de grafite, GO e RGO.

Microscopia Eletrônica de Varredura (MEV): A Figura 9 mostra as imagens de Microscopia Eletrônica de Varredura - MEV referente a amostra comerciais obtidas da Sigma Aldrich depositadas sob uma lâmina de silício. O MEV realça aspectos de monocamadas e multicamadas pelo contrate brilhante das amostras, é bastante perceptível, ao observa-se a transparência ou semi opacidade ("sombras") em regiões de camadas dobradas ou multicamadas. 


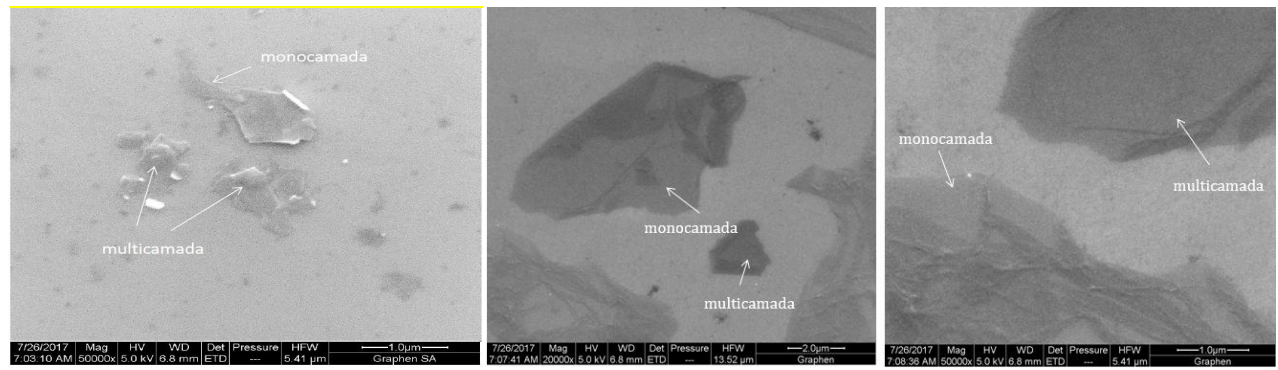

Figura 9 - Micrografias de MEV do óxido de grafeno e do óxido de grafeno reduzido obtido da Sigma Aldrich sob lâmina de silício, com aumento de 20.000x e 50.000x.

Microscopia Eletrônica de Transmissão (MET): As micrografias MET do GO e RGO são apresentados na Figura 10 (a e b). Pode-se observar, na Figura 10a, o aspecto do GO, como também mostrado pela análise de MEV (Figura 9), que uma película fina é totalmente transparente, aparentemente flexível com aspecto também aparentemente "amarrotada". Já a micrografia do RGO (Figura 10b) é bastante semelhante ao observado anteriormente por MEV. Através de ambas as micrografias é possível estimar a espessura das amostras é da ordem de alguns nanômetros e sua largura/comprimento em alguns micrometros.

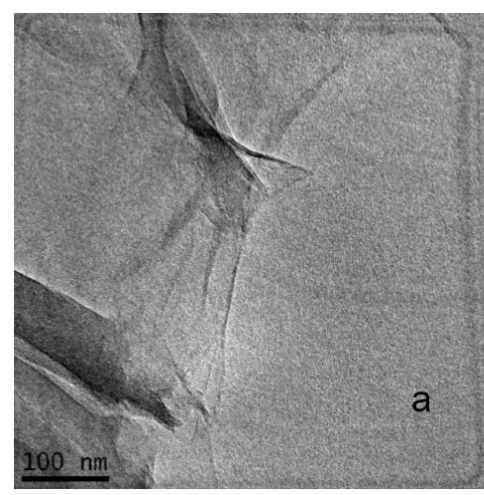

Cordeiro et al. 2015

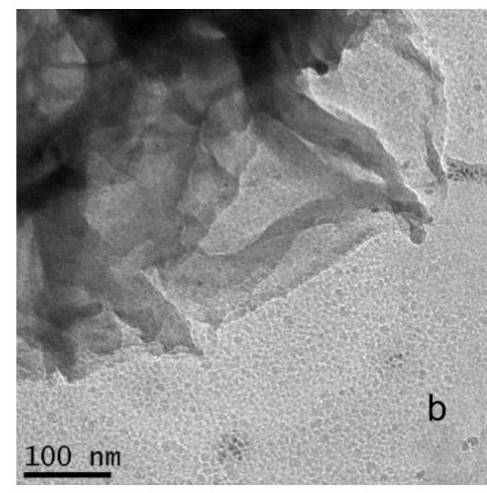

Figura 10. Micrografias MET do óxido de grafeno GO (a) e do grafeno reduzido RGO (b).

Espectroscopia Raman: A espectroscopia Raman é uma técnica amplamente utilizada para a caracterização de materiais carbonosos, identificando os tipos de ligações e fornecendo informações sobre o grau de desordem da rede cristalina. Os espectros Raman de todos os materiais carbonosos exibem picos característicos na região entre 1000 e $1800 \mathrm{~cm}^{-1}$ para energia de excitação no visível e infravermelho. Para os materiais grafíticos, essa região é referente às bandas $\mathrm{D}, \mathrm{G}$ e $\mathrm{D}^{\prime}$, onde a banda $\mathrm{G}\left(1500 \mathrm{a} 1600 \mathrm{~cm}^{-1}\right)$ é um modo de primeira ordem com simetria E2g e as banda D (1200 a $\left.1400 \mathrm{~cm}^{-1}\right)$ e D' $\left(1600-1630 \mathrm{~cm}^{-1}\right)$ surgem devido a processos Raman de dupla ressonância. (LOBO et al., 2005). O espectro do óxido de grafeno é caracterizado pela presença do pico $\mathrm{D}\left(1350 \mathrm{~cm}^{-1}\right)$ de intensidade menor ou semelhante ao pico G. 
Óxido de grafeno reduzido são produto da redução de óxido de grafeno por tratamento térmico, químico ou elétrico. A Figura 11 mostra aspectos dos espectros Raman de óxido de grafeno (GO) e óxido de grafeno reduzido (RGO). A estrutura gerada apresenta ainda alguns grupos funcionais oxigenados e grande número de defeitos.

O espectro Raman do RGO é caracterizado pela presença do pico D de maior intensidade que o pico $\mathrm{G}$.
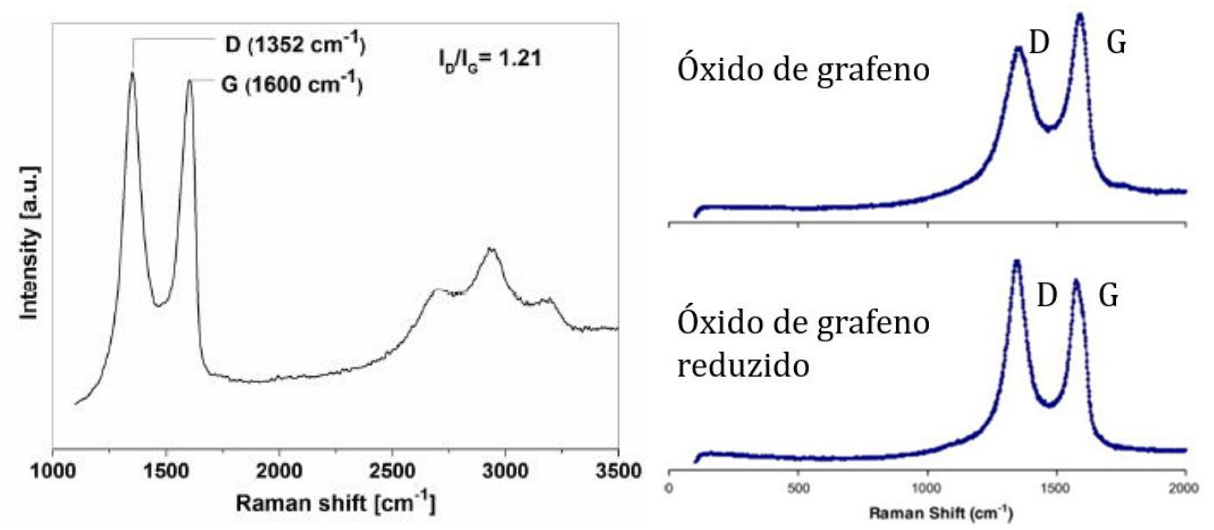

Figura 11 - Espectros Raman de óxido de grafeno (GO) e óxido de grafeno reduzido (RGO), respectivamente.

A microscopia ótica acoplada a espectroscopia Raman permite também identificar regiões de monocamadas e regiões dobradas, confirmadas pelo padrão do espectro Raman na região de transparência Figuras 12 e 13.

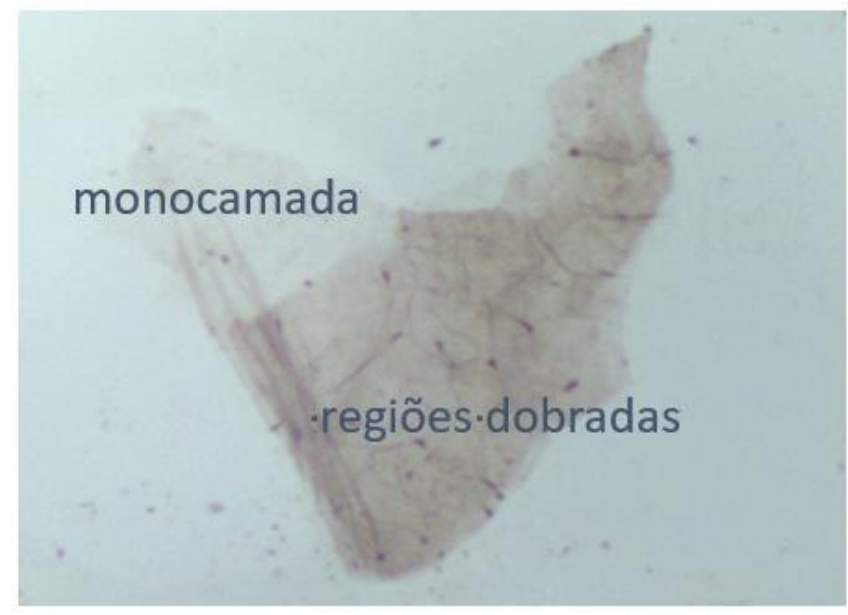

Figura 12 - Micrografia do óxido de grafeno reduzido obtido pela Sigma Aldrich, em microscópio óptico acoplado ao espectrometro Raman. Aumento de 100x. 


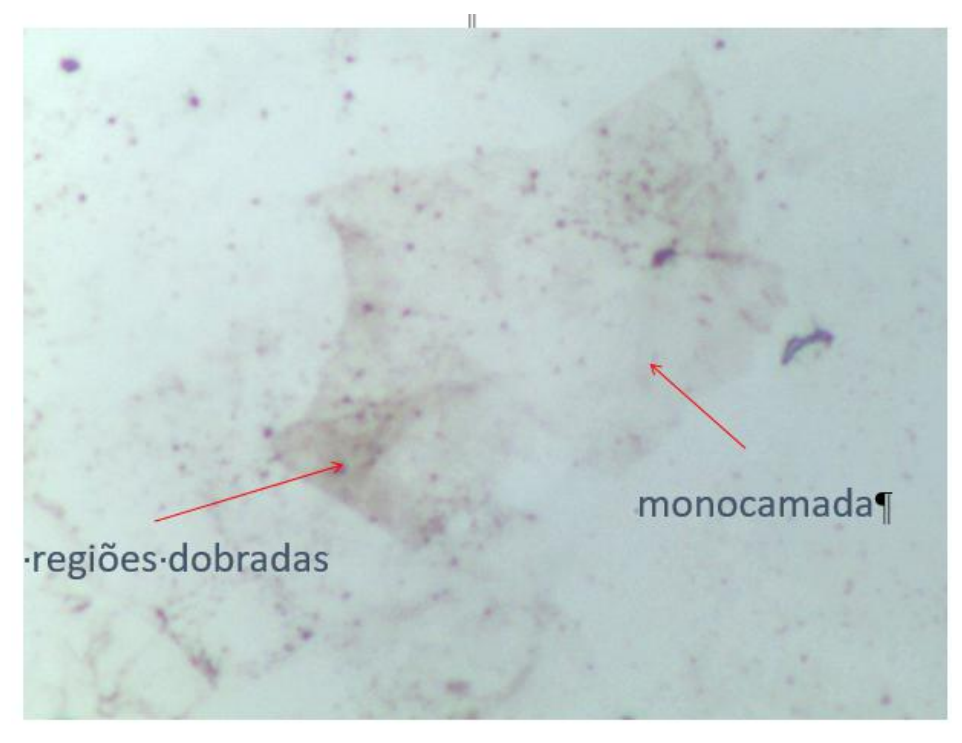

Figura 13 - Micrografia do óxido de grafeno reduzido obtido pela Sigma Aldrich, em microscópio óptico acoplado ao espectrometro Raman. Aumento de 100x.

Com base nestes resultados, pode-se afirmar que o processo de síntese de grafeno e de óxidos de grafenos a partir de grafite em pós é efetivo e de fácil implementação. Além disto, é um processo que pode ser implementado com custos relativamente baixos em termos de reagentes e infraestrutura necessárias. Dentre suas desvantagens ainda está o meio fortemente ácido e/ou oxidante, o que pode gerar efluentes potencialmente danosos, embora seja um processo aprimorado no sentido de diminuir seu impacto ambiental, por meio da geração de co-produtos para a área agrícola ou inertizando seus efeitos químicos.

Uma das primeiras aplicações comerciais do grafeno em grande escala será possivelmente em baterias que carregam mais rapidamente que as baterias convencionais de hoje, podendo reduzir o tempo de carregamento de até 3 ordem de grandeza. Já o óxido de grafeno também poderá ser utilizado na extração do cloreto de sódio da água do mar e de substâncias radioativas em soluções aguosas. Na área de saúde, tanto com o grafeno como com o óxido de grafeno, vêm sendo aprimoradas aplicações clínicas na forma de compósitos de matrizes de biocerâmicas ou biomateriais polimericos (hidroxiapatita, biovidros, PMMA, PU, dentre outros) como reforços mecânicos de dispositivos implantes ou na estruturas e funcionalização de biossensores. No meio ambiente e na alimentação humana, o óxido de grafeno vem se mostrando capaz de remover de forma eficiente metais pesados da água.

\section{CONCLUSÃO}

As diferentes rotas estudadas apresentam pontos favoráveis e desfavoráveis, sendo que a aplicação final do produto é o que determina na escolha do método mais adequado. Os métodos de esfoliação mecânica, crescimento epitaxial e deposição química de vapor (CVD) produzem um grafeno com mínimos defeitos na estrutura, porém são caros e não podem ser produzidos em escala comercial. São ideais para a confecção de filmes por exemplo. Em contrapartida, o método de esfoliação química gera grafeno com diferentes graus de defeitos, 
mas que pode ser usado por exemplo para a produção de compósitos. A produção é de custo mais baixo e elevado rendimento. A técnica mais relevante para caracterizar grafeno é a espectroscopia RAMAN.

\section{AGRADECIMENTOS}

Agradecemos à CAPES, à FAPEMIG e ao CEFET-MG pelo apoio e incentivo.

\section{REFERÊNCIAS}

BADHULIKA, S. et al. Graphene hybrids: synthesis strategies and applications in sensors and sensitized solar cells. Frontiers in Chemistry, v. 3, n. 38, 2015.

CASTRO, M. O. Síntese de grafeno pelo método CVD. Dissertação de mestrado, Universidade Federal do Ceará, 2011.

CORDEIRO, G. L. et al. Síntese Química e Caracterização de Grafeno. $59^{\circ}$ Congresso Brasileiro de Cerâmica, p. 2324 -2332, 2015.

EUROPEAN COMMISSION. Graphene and Human Brain Project win largest research excellence award in history, as battle for sustained science funding continues. http://europa.eu/rapid/press-release_IP-13-54_en.htm (date of access: 24/11/2015). IP/13/54, 2013.

FIM, F. C. Síntese de propriedades de nanocompósitos de polietileno/nanolâminas de grafeno obtidos através de polimerização in situ. Tese de Doutorado, Universidade Federal do Rio Grande do Sul, 2012.

HACK, R. Nanocompósitos Poliméricos Multifuncionais Reforçados com Grafeno. Dissertação de mestrado, Universidade do Estado de Santa Catarina, 2013.

HUMMERS, W. S. \& OFFEMAN, R. E. Preparation of Graphitic Oxide, J. Am. Chem. Soc. 80, 1339-1339, 1958.

LOBO, A. O et al. Caracterização de materiais carbonosos por espectroscopia RAMAN. Revista Brasileira de Aplicações de Vácuo, v.24, n. 2, 98-103, 2005.

MCALLISTER, M. J. et al. Single sheet functionalized graphene by oxidation and thermal expansion of graphite. Chemistry of Materials 19, p. 4396-4404, 2007.

MEHL, H; MATOS C. F; NEIVA, E. C; DOMINGUES, S. H; ZARBIN, A. J. Efeito da Variação de Parâmetros Reacionais na Preparação de Grafeno Via Oxidação e Redução do Grafite. Química Nova, v. 37, nº 10, p.1639-1645, 2014.

NOVOSELOV, K. S. et al. Electric field effect in atomically thin carbon films. Science 306, p. 666-669, 2004.

PAROBEK, D. et al. Synthesizing and Characterizing Graphene via Raman Spectroscopy: An Upper-Level Undergraduate Experiment That Exposes Students to Raman Spectroscopy and a 2D Nanomaterial. Journal of Chemical Education, 93, p.1798-1803, 2016. 
$\mathrm{POH}, \mathrm{H}, \mathrm{L}$ et al. Graphenes prepared by Staudenmaier, Hofmann and Hummer methods with consequent thermal exfoliation exhibit very different electrochemical properties. Nanoscale. v. 7;4(11), p. 3515-22, 2012.

REINA, A. et al. Large area, few-layer graphene films on arbitrary substrates by chemical vapor deposition. Nano Letters 9, p. 30-35, 2009.

SANTOS, F. S N Novo processo de produção de óxido de grafeno à temperatura ambiente. In: CONGRESSO TÉCNICO CIENTÍFICO DA ENGENHARIA E DA AGRONOMIA, 2016, Foz do Iguaçu

SOLDANO C; MAHMOOD A; DUJARDIN E. Produção, propriedades e potencial do grafeno. Carbon. 2010, 48: 2127-2150.

WHITENER Jr., K.; SHEEHAN, P. E. Graphene synthesis. Diamond Relat. Mater., v. 46, p.25-34, 2014.

WICK, P. et al. Classification framework for graphene-based materials. Angewendte Chemie. Switzerland, v. 53, p. 7714-7718, 2014.

WONG, C. H. A. et al. Synthetic routes contaminate graphene materials with a whole spectrum of unanticipated metallic elements. Proceedings of the National Academy of Sciences, v. 111, n. 38, p. 13774-13779, 2014.

UIPAC https://abqrs.com.br/ <Acesso em 07.agosto.2017>

ZARBIN, A. J. G; OLIVEIRA, M. M. Carbon nanostructures (nanotubes and graphene): Quo Vadis?. Quím. Nova, v.36, n 10, p.1533-1539, 2013. 